\title{
Knowledge Based Organization
}

\author{
An identification model \\ Cristina Denisa Neagu \\ Business Information Systems Department, \\ Faculty of Economics and Business Administration \\ Al. I. Cuza Iasi University \\ Bvd. Carol I, Nr. 22, Iasi, 700505, Romania \\ dneagu@uaic.ro
}

\begin{abstract}
In the recent years, terms like knowledge society, intelligent, learning or knowledge based organizations are used more often. Related to these concepts, many studies underline the fact that organizations should act intelligently by learning and using their knowledge or by being just knowledgebased organizations. The majority of these studies are suffering from being too much philosophical in describing the organization of the future. This philosophical approach limits the possibility of comparison and analysis of organizations based on their potential of being more or less knowledge based. The purpose of this paper is to support the analysis of organizations based on their potential for acting intelligently. After the literature review, this paper provides a model for evaluating and identifying how much an organization could be included in the category of knowledge based organizations. It continues with the presentation of the proposed identification model and it concludes with the analysis results based on this model application in a Romanian company selected for the case study.
\end{abstract}

\section{Introduction}

The socio-economic life is based on knowledge and especially in the last years, knowledge have gained more attention being perceived as a strategic asset, as the key resource for organizations, knowledge which is further embedded in the products and services available on the market. In these conditions, concepts such as knowledge based organization, intelligent or knowledge creating company have gained a lot in number of studies related to them. Other concepts like the old one of the organizational structure suffer transformations and a relatively new concept like knowledge worker creates contradictions. Which type of the organizational structure is the best, the flatter one or the bureaucratic, hierarchical but flexible one? Who is knowledge worker, any specialist, expert in his domain of activity, no matter the education or only highly educated people?

Answering to these questions is highly required in indentifying what differentiates one organization from another which has the same physical assets. This paper purpose is to establish an order in the Pandora's Box of knowledge-based organization concept's complexity by answering to these questions in a more elaborated way.

Please use the following format when citing this chapter:

Neagu, C.D., 2008, in IFIP International Federation for Information Processing, Volume 262; The Future of Identity in the Information Society; Simone Fischer-Hübner, Penny Duquenoy, Albin Zuccato, Leonardo Martucci; (Boston: Springer), pp. 407-421. 


\subsection{Known results}

Knowledge based organization have nowadays became widely an important research topic. Most researchers are focused on one or some of aspects related to this concept, such as: types of knowledge, organizational learning and organizational knowledge, knowledge assets and their specific processes which allow knowledge to be acquired, applied, stored, transferred and organizational strategies in order to support and / or improve the knowledge use inside and outside organization.

Several studies are underling the fact that knowledge is the primary resource in the organizations of the 21 st century. Further more, the knowledge flows are becoming more important than the financial flows, the employees are revenue creators, the organizational hierarchical structure has fewer levels and so on. The managers are becoming leaders and they are focused on employee's career development and on supporting the organizational learning and continuum innovation. All these statements are insufficient for clarifying why one organization is "smarter" than another because they are highly and firmly connected to the philosophical approach. Furthermore, all the aspects mentioned above are presented partially and sometimes in a confusing way. In order to offer some clarification in this domain, we will use their integration in one identification model.

\subsection{Our results}

This paper tries, after the literature review, to identify the characteristics of knowledge based organizations and to provide a complete definition for this concept. Building on these characteristics, further criteria will be developed and integrated in an identification model which will allow analyzing and indentifying the potential of being knowledge based organization.

This model is called an identification model based on the fact that is limited to aspects such as: 1) human resources as knowledge workers; 2) the knowledge-creation processes; 3) the organizational culture and 4) the organizational structure; 5) the management and 6) the information infrastructure. It doesn't include a model for measuring the organizational knowledge assets; this is partially included in the intellectual capital evaluation models and it would be a subject for another paper.

Finally, the paper will apply this model on a Romanian organization where direct observation, unstructured interviews and questionnaire were used in order to get the real image of this organization and analyze it in order to identify its possible characteristics as knowledge based organization. 


\section{Preliminaries}

\subsection{Problem description}

In the process of providing a more clear description of the knowledge based organization, we have started by analyzing, based on the literature addressing this concept, how the organization of the knowledge society should look like. We have selected several definitions as being related to the knowledge-based organization and have extracted the aspects which will be used (along with others) in the identification model.

Table 1 highlights the core aspects which should be analyzed, such as: human resources, knowledge-creation processes, organizational culture, structure and management. We consider that there is another vital aspect like the existence of an information infrastructure capable to support the employees and the knowledge creation processes and continuum flow of knowledge inside and between organizations.

Concerning the workforce inside this type of company, the employees should be knowledge workers, which could be tackled from two different perspectives. The permissive perspective (Drucker [7]; Collins [8]) is based on the principle that "no matter what we do we are all, in some form or other, knowledge workers". The restrictive perspective (Despres and Hiltrop [9]; Standfield [10]; Barrow and Loughlin [11]) includes in the category of knowledge workers only highly educated employees (for Davenport [12] secondary education is not enough to be a knowledge worker); knowledge work - involves using four main assets, such as: 1) knowledge; 2) relationship; 3) emotional; 4) time assets Standfield [10]. These assets are used in the process of knowledge creation based on the conversion of two main types of knowledge: explicit and tacit and the conversion processes are: socialization, externalization, combination and internalization (Nonaka [2]).

The knowledge workers are main actors in the knowledge creation inside the company and not only. The knowledge creation can effectively take place in an environment which promotes and supports communication, trust, freedom to innovate and improvise (Wiig [5]);

From the organizational structure point of view, a knowledge based organization could be 1) flatter with less hierarchical levels (see Drucker [13] and the symphony organization) or 2) hierarchical but flexible one combining three layers - bureaucratic layer with project team layers and knowledge layer (Nonaka [6]).

The management has the role to create and promote the vision and strategies for knowledge-conversion processes both internally and externally to the organization (Nonaka [6])

The communication and collaboration between knowledge workers in the knowledge-creation processes are and should be supported by the information and communication technologies. These are both conditions (involving knowledgeable users) and supporting tools (speeding up the information and knowledge transfer). Taking this into consideration, managers have to find and implement the right information infrastructure in order to ensure the knowledge creation and 
dissemination both inside and also externally by being involved in bigger knowledge networks from which knowledge can be acquired Maier [14].

Table 1. Possible definitions for the knowledge-based organization.

\begin{tabular}{|c|c|c|}
\hline Concept & Definition & Elements \\
\hline $\begin{array}{l}\text { Knowledge } \\
\text { based- } \\
\text { organization } \\
\text { Liebowitz } \\
\text { [1] }\end{array}$ & $\begin{array}{l}\text { "An entity that realizes the importance of its } \\
\text { knowledge, internal and external to the } \\
\text { organization, and applies techniques to maximize } \\
\text { the use of this knowledge to its employees, } \\
\text { shareholders, and customers" }\end{array}$ & $\begin{array}{l}\text { Knowledge- } \\
\text { important internally } \\
\text { and externally }\end{array}$ \\
\hline $\begin{array}{l}\text { Knowledge } \\
\text { creating } \\
\text { company } \\
\text { Nonaka [2] }\end{array}$ & $\begin{array}{l}\text { Organization "that consistently create new } \\
\text { knowledge, disseminate it widely throughout the } \\
\text { organization, and quickly embody it in new } \\
\text { technologies and products". }\end{array}$ & $\begin{array}{l}\text { Consistent } \\
\text { knowledge creation } \\
\text { in entire } \\
\text { organization and } \\
\text { which is embodied } \\
\text { in new technology } \\
\text { and products }\end{array}$ \\
\hline $\begin{array}{l}\text { Learning } \\
\text { organization } \\
\text { Argyris and } \\
\text { Schon [3], } \\
\text { Senge [4] }\end{array}$ & $\begin{array}{l}\text { "When members of the organization act as learning } \\
\text { agents for the organization, responding to changes } \\
\text { in the internal and external environments of the } \\
\text { organization by detecting and correcting errors" } \\
\text { "Organizations where people continually expand } \\
\text { their capacity to create the results they truly desire, } \\
\text { where new and expansive patterns of thinking are } \\
\text { nurtured, where collective aspiration is set free, and } \\
\text { where people are continually learning to learn } \\
\text { together" }\end{array}$ & $\begin{array}{l}\text { Employees - } \\
\text { learning agents } \\
\text { Detecting and } \\
\text { correcting errors } \\
\text { Employees learn } \\
\text { together } \\
\text { Collective aspiration } \\
\text { is free }\end{array}$ \\
\hline $\begin{array}{l}\text { Intelligent } \\
\text { organization } \\
\text { Wiig [5] }\end{array}$ & $\begin{array}{l}\text { "Organization which acts effectively in the present } \\
\text { and its capable to deal effectively with the } \\
\text { challenges of the future. Its meets its objectives by } \\
\text { implementing its visions and strategies through its } \\
\text { systems, policies and organizational structure". }\end{array}$ & $\begin{array}{l}\text { Employees - based } \\
\text { on their skills, have } \\
\text { the freedom to } \\
\text { innovate and } \\
\text { improvise and have } \\
\text { to act intelligently } \\
\text { by using effective } \\
\text { and active } \\
\text { communication }\end{array}$ \\
\hline $\begin{array}{l}\text { Hypertext } \\
\text { organization } \\
\text { Nonaka [6] }\end{array}$ & $\begin{array}{l}\text { The core feature of the hypertext organization is the } \\
\text { ability to switch between the various context of } \\
\text { knowledge creation, to accommodate changing } \\
\text { requirements from situations both inside and } \\
\text { outside the organization. }\end{array}$ & $\begin{array}{l}\text { The organizational } \\
\text { structure with two } \\
\text { real layers (business } \\
\text { units and project } \\
\text { teams) and one } \\
\text { conceptual } \\
\text { (knowledge layer) }\end{array}$ \\
\hline
\end{tabular}

In our opinion, a knowledge based organization is an organization which 1) acts intelligently and successfully in its domain by learning and creating knowledge in a continuum way, 2) uses its knowledge (both the tacit - resident in employees' minds and the explicit which is embedded in the work procedures, databases, etc.) 3) by creating and implementing the right organizational culture (characterized by freedom 
to innovate and experiment) 4) supported by a flexible organizational structure (hierarchic structure combined with multifunctional, efficient and ad-hoc created and efficient project teams) and 5) by the right combination of information and communication technologies in order to cover all four processes of knowledge conversion both internally and externally to the organization.

\subsection{The identification model's components}

"An organization is defined by the way in which the work is being done. The purpose of one organization is to get the work done. This requires a structure. Also, an organization is, above all, social. It is people. Its purpose must therefore be to make the strengths of people effective" Drucker [15].

Having this statement in our mind, we have decided to elaborate one model in order to identify if an organization has the features for being considerate as being knowledge based. The elements to be analyzed are: 1) the human resources; 2) the knowledge creation; 3) the organizational culture and 4) structure and 5) the management and 6) the information infrastructure.

The employees, knowledge workers, are the owners of the most important and valuable resource of one organization, knowledge. Their knowledge skills are highly important in identifying the possible knowledge-based feature of one company. In order to evaluate the employee's knowledge skills, we have combined the hierarchy of skills provided by Johnson [16]) and the skills provided by education:

Table 2. Knowledge worker's skills (adapted from Johnson [16]).

\begin{tabular}{|l|l|}
\hline Knowledge skills & Education \\
\hline Basic & Secondary + Tertiary + Life Long Learning \\
\hline Professional & Secondary + Tertiary + Life Long Learning \\
\hline Technological & Secondary + Tertiary + Life Long Learning \\
\hline $\begin{array}{l}\text { Information Problem Solving and } \\
\text { Higher Thinking }\end{array}$ & Tertiary + Life Long Learning \\
\hline Conceptual & Life Long Learning \\
\hline
\end{tabular}

The knowledge creation should take place through all four processes of knowledge conversion and their specific methods:

Table 3. Knowledge creation and its methods ([2], [6], [17], [18] [19]).

\begin{tabular}{|l|l|}
\hline Conversion & Methods \\
\hline Socialization & $\begin{array}{l}\text { a) Apprenticeship; b) Shared experiences; c) On-the-job training; d) Joint } \\
\text { activities; e) Physical proximity; f) Walking in the company; g) Informal } \\
\text { meetings outside the workplace; h) Wandering outside the company }\end{array}$ \\
\hline Externalization & a) Use of metaphors and analogies; b) Dialogue; c) Self-reflection \\
\hline Combination & $\begin{array}{l}\text { a) Use different data sources; b) Meetings and telephone conversations; c) } \\
\text { Presentations; d) Using ICTs }\end{array}$ \\
\hline Internalization & $\begin{array}{l}\text { a) Learning-by-doing; b) Focused training with senior colleagues; c) } \\
\text { Simulation/experiments; d) Self-reflection upon documents; e) Reflection } \\
\text { with others }\end{array}$ \\
\hline
\end{tabular}


The organizational culture should promote the knowledge transfer between employees.

Table 4. Organizational culture (adapted from Goffee and Jones [20]).

\begin{tabular}{|l|l|}
\hline Aspects of the culture & Scale \\
\hline Sociability & 1) Very weak; 2) Weak; 3) Neutral; 4) Strong; 5) Very strong \\
\hline Solidarity & 1) Very weak; 2) Weak; 3) Neutral; 4) Strong; 5) Very strong \\
\hline Knowledge transfer & 1) Very rarely; 2) Rarely; 3) Neutral 4) Regular; 5) Daily \\
\hline Physical space & 1) Highly closed; 2) Closed; 3) Neutral; 4) Open; 5) Highly open \\
\hline Communication & $\begin{array}{l}\text { 1) Highly formal; 2) Formal; 3) Neutral; 4) Informal; 5) Highly } \\
\text { informal }\end{array}$ \\
\hline Flexible schedule & 1) Very rarely; 2) Rarely; 3) Neutral 4) Regular; 5) Daily \\
\hline Identity & $\begin{array}{l}\text { 1) High individualism; 2) Individualism; 3) Neutral; 4) Some } \\
\text { similarities; 5) Strong similarities }\end{array}$ \\
\hline
\end{tabular}

The organizational structure, in mainly all companies, is still mainly hierarchical. In these conditions, we use Nonaka's point of view about the hypertext organization based on flexible structure and the role played by project teams in the knowledgecreation processes [6].

Table 5. Organizational structure.

\begin{tabular}{|l|l|}
\hline Aspects & Scale \\
\hline Use & 1) Very rarely; 2) Rarely; 3) Neutral 4) Regular; 5) Daily \\
\hline Flexibility & 1) Highly rigid; 2) Rigid; 3) Neutral; 4) Flexible; 5) Highly flexible \\
\hline Creation & $\begin{array}{l}\text { 1) Imposed by the procedures; 2) Imposed by the bosses; 3) At } \\
\text { demand; 4) Voluntarily; 5) Ad hoc }\end{array}$ \\
\hline Variety & $\begin{array}{l}\text { 1) One domain - one department; 2) One domain - more departments; } \\
\text { 3) More domains and internal experts 4) One domain - internal experts } \\
\text {-one external expert; 5) More domains - internal and external experts }\end{array}$ \\
\hline Physical space & $\begin{array}{l}\text { 1) Highly functional; 2) Functional; 3) Neutral; 4) Weak structure; 5) } \\
\text { Unstructured }\end{array}$ \\
\hline Efficiency & 1) Very weak; 2) Weak; 3) Neutral; 4) Good; 5) Very good \\
\hline
\end{tabular}

The management should move to a new direction in offering more freedom and training to organization's employees, but also has to take into consideration aspects such as:

Table 6. Management.

\begin{tabular}{|l|l|}
\hline Aspects & Scale \\
\hline Autonomy & $\begin{array}{l}\text { 1) High supervision; 2) Some supervision; 3) Neutral; 4) Some freedom; } \\
\text { 5) High freedom }\end{array}$ \\
\hline Empowerment & $\begin{array}{l}\text { 1) Highly subjective; 2) Subjective; 3) Neutral; 4) Objective; 5) Highly } \\
\text { objective }\end{array}$ \\
\hline Evaluation & $\begin{array}{l}\text { 1) Highly subjective; 2) Subjective; 3) Neutral; 4) Objective; 5) Highly } \\
\text { objective }\end{array}$ \\
\hline Incentives & $\begin{array}{l}\text { 1) Highly subjective; 2) Subjective; 3) Neutral; 4) Objective; 5) Highly } \\
\text { objective }\end{array}$ \\
\hline
\end{tabular}




\begin{tabular}{|l|l|}
\hline $\begin{array}{l}\text { Accessibility to } \\
\text { knowledge }\end{array}$ & $\begin{array}{l}\text { 1) Highly restrictive; 2) Restrictive; 3) Neutral; 4) Access under control; } \\
\text { 5) Highly accessible }\end{array}$ \\
\hline Communication & $\begin{array}{l}\text { 1) Mainly inside the department; 2) On the same level; 3) Both inside } \\
\text { the department and on the same level; 4) Between different levels; 5) } \\
\text { Mainly between levels and with external environment }\end{array}$ \\
\hline $\begin{array}{l}\text { Openness to } \\
\text { ideas }\end{array}$ & $\begin{array}{l}\text { 1) Highly restrictive 2) Restrictive; 3) Neutral; 4) Some openness; 5) } \\
\text { Highly open }\end{array}$ \\
\hline
\end{tabular}

The information infrastructure in one knowledge-based organization should contain information technologies able to cover all four knowledge conversion processes. The available technologies are grouped in table 7 .

Table 7. ICTs for knowledge based organization (Nonaka [2] and Maier [14]).

\begin{tabular}{|l|l|}
\hline Conversion & Technology \\
\hline Socialization & $\begin{array}{l}\text { Groupware, Expertise location, Knowledge Map Systems, Visualization } \\
\text { tools, Instant Messaging, Email, Knowledge Portals }\end{array}$ \\
\hline Externalization & $\begin{array}{l}\text { Groupware, Newsgroups, Forums, Instant messaging, Email, Workflow } \\
\text { systems, Artificial Intelligence, Knowledge Portals }\end{array}$ \\
\hline Combination & $\begin{array}{l}\text { Search Engines, Workflow, Innovation Supporting Tools, Competitive } \\
\text { Intelligent tools, BI (Business Intelligence), Document and content } \\
\text { management systems, ERP Systems, Intranet, Voice / Speech } \\
\text { Recognition, Search Engine, Taxonomy, Knowledge Portals }\end{array}$ \\
\hline Internalization & eLearning, Computer Based Training, Innovative supporting tools \\
\hline
\end{tabular}

\subsection{Model's methodology and applicability}

The model for identification of knowledge based organizations takes into consideration six strategic criteria such as: human resources, knowledge creation, organizational culture, structure, management and information infrastructure. Each criterion contains sub-criteria with two exceptions: human resources (levels of knowledge skills) and knowledge creation (knowledge-conversion processes).

The evaluation scale for the each of six criteria included in the model is from 1 to 5 and it was already presented in the model's description, except the one for the human resources. The scale is: 1) Very weak, 2) Weak, 3) Neutral, 4) Good, 5) Excellent. The value of each of the six criteria (except for human resources) is the average of value of each sub-criterion. The formula for identifying the staff skills for each level from the Jones model is: the staff covering the specific level skills as \% from the company's workforce X 5/100. The human resources capacity to sustain a knowledge-based organization is identified through the next formula: Human resources skill level $=0.05 \mathrm{X}$ Basic $+0.1 \mathrm{X}$ Professional $+0.2 \mathrm{X}$ Technological +0.3 $\mathrm{X}$ Informational $+0.35 \mathrm{X}$ Conceptual. The scale used to identify the level of knowledge creation inside the company is: 1) Never; 2) Occasionally; 3) Often; 4) Regular; 5) Daily.

The individual results of all six criteria have values between 1 and 5 . The final result is an average of the values for all six aspects analyzed. The final evaluation 
scale is 1) Very limited knowledge-based, 2) Very weak, 3) Weak, 4) Good, 5) Excellent.

As it results from the evaluation scale, each organization is based on knowledge but the difference is the level of its dependency on knowledge showed by the value for each six criteria. For results lower or equal with 3, the organization is weakly knowledge based and has to develop strategies in order to transform its weaknesses in strengths.

This model could be used in the SWOT analysis in order to develop strategies for organizational development. The application of this model could explain why one organization is performing better than another one in the innovation process. Although it stays in the philosophical approach of the knowledge-based organization concept, by being mainly qualitative than quantitative, organizations could use this model in the initial phase of identifying their organizational intelligence. The model could be extended to a wider area of strategic assets which provides organizational uniqueness on the market and the organization's success in the knowledge society.

\section{The Romanian case study}

\subsection{Company description}

The company selected for the case study is a Romanian public organization, the biggest in the north-east of Romania. It has an organizational structure with five levels organized in three main divisions 1) economic, 2) technique and 3) production which is the largest because it covers the company's main activity and the majority of employees.

The human resources structure is represented by $85 \%$ of employees with secondary education. $80 \%$ of them are working at the operative level, mainly outside the office and they are part of the production division. The information infrastructure is available only for top and middle managers and administrative and technical staff (around $20 \%$ of the employees).

The analysis of the Romanian company was based on three methods, such as: questionnaire, direct observation and unstructured interviews. The questionnaire was used in the case of top and middle managers and administrative and technical staff. The direct observation and unstructured interviews were used in the case of employees from the operative level.

\subsection{The analysis results in the case of managerial, technical and administrative departments}

The questionnaire (response rate - $91.1 \%$.) was organized based on the identification model presented above and had six sections such as: 1) human resources, 2) organizational culture, 3) management, 4) knowledge sources 5) organizational structure and 6) information systems. 
The managerial, technical and administrative departments have human resources with a low level of knowledge needed for using ICTs (2.87), but they have good information (4.55) and conceptual skills (4.34). Taking this into consideration, along with the model of Johnson [16], the average for the human resources in the case of departments mentioned above is 4.06 which imply that these employees are specific to and able to support a knowledge based organization.

Table 8. The analysis results for the managerial, technical and administrative departments.

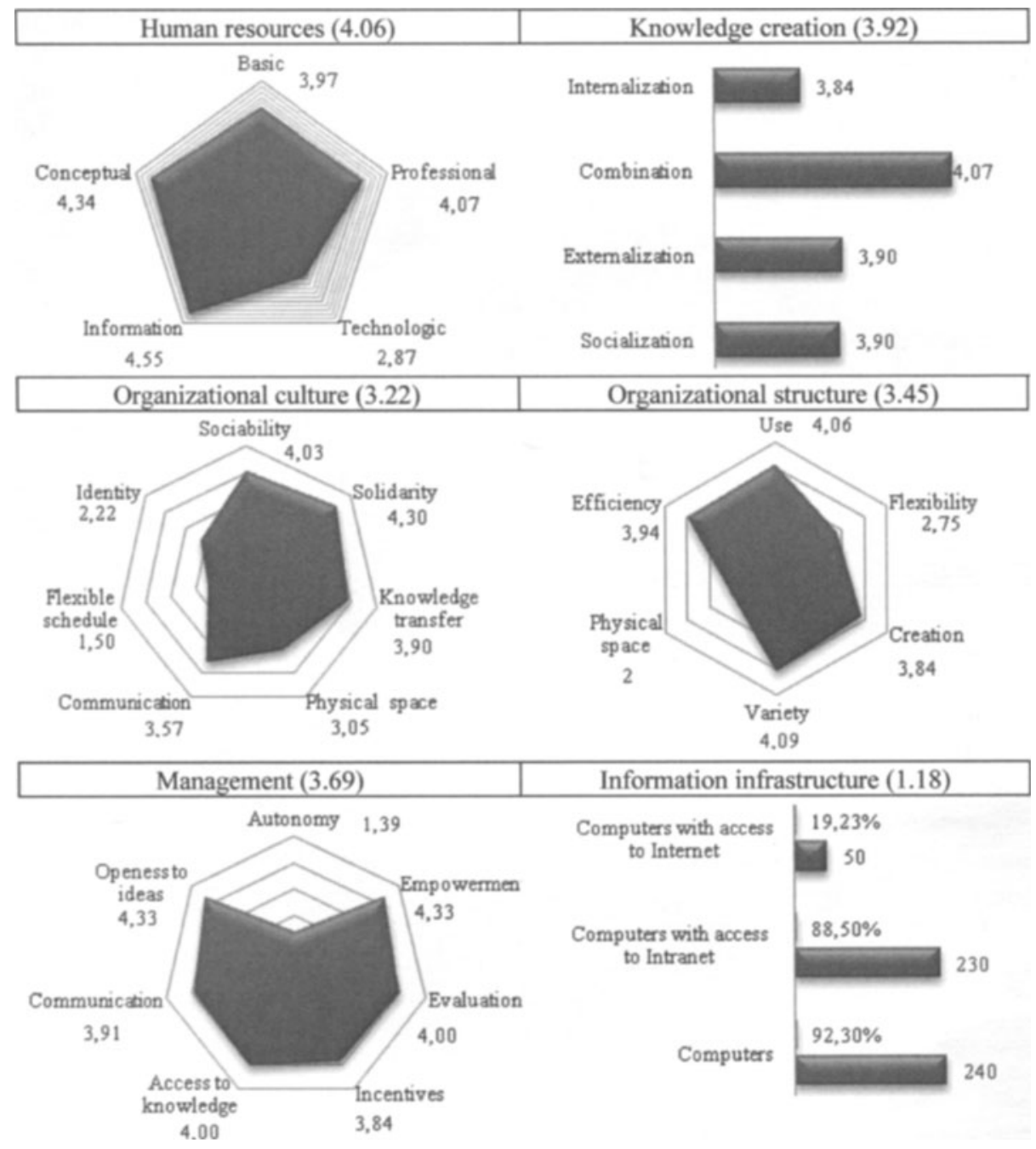

The knowledge creation (3.92) takes place, in this case, mainly through meetings and telephone conversations, presentation of projects and their results, use of scientific data (through ICTs or library's resources) and the knowledge is accumulated in documentations, which are also source of knowledge for new employees. 
Knowledge is converted, at this level, mainly through combination (4.07), but also externalization and socialization (3.9).

The strengths of organizational culture (3.22) are: solidarity (4.3), sociability (4.03), and knowledge transfer (3.9). The weaknesses of the organizational culture are flexible working program (1.5) and identity (2.22). At this level, the organizational structure (3.45) needs improvements in order to support the knowledge based organization by focusing on increasing the flexibility of the teams (2.75) and the space allocated for their meetings (2). Teams have a good variety (employees with different backgrounds) (4.09) and the use of project teams is promoted (4.06) and the available teams have a good efficiency (3.94).

The management (3.69) in the managerial, administrative and technical departments has the capacity to sustain a knowledge based organization. The only weak aspect is the autonomy of employees in taking decisions (1.39).

The information infrastructure is at a very low level (1.18), unable to support a knowledge based organization. The analysis of the questionnaire for these criteria highlights the fact that employees understand and specify the need to implement: an organizational portal, an integrated electronic environment for supporting communication between employees, a specific area on the organizational portal dedicated to eLearning and an electronic journal with all employees, their domains of expertise and their contact details.

The average of the results for the six criteria is 3.25 , which indicates that the Romanian company is a knowledge based organization but in the initial phase. The company has to invest mainly in the information infrastructure provided for its managerial, technical and administrative employees. Other aspects to be taken into consideration are organizational culture and a wider and efficient use of teams in order to increase the organizational structure's flexibility.

\subsection{The analysis's results including the production departments}

At the entire organizational level, including the production division which covers around $80 \%$ of the company's activity, the methods used in order to analyze the organization were direct observation and unstructured interviews. The analysis results are presented in table 9.

The level of human resources from the knowledge workers point of view is a very low level (1.24) and is determined by the fact that the activity inside the company involves mainly physical force and only $10 \%$ of employees have tertiary education. Furthermore, the majority of employees (around 80\%) don't have the necessary skills for using ICTs.

The main knowledge creation (3.17) takes place through socialization (3.81), more precise through observation, imitation and apprenticeship. The second most important knowledge-conversion process is combination (3.03) which is specific to employees working in the managerial, technical and administrative departments.

The organizational culture (3) needs improvement in order to be able to support a knowledge based organization. The most important aspects which needs improvement 
is the knowledge transfer that could be solved through a highly promoted and motivated dissemination of knowledge in the entire organization.

The organizational structure (2.83) doesn't have the capacity to support a knowledge based organization because although is using teams for reaching specific objectives, these teams have a low efficiency, flexibility and diversity (are formed mainly from employees from the same department).

Table 9. Analysis results at the entire organizational level.

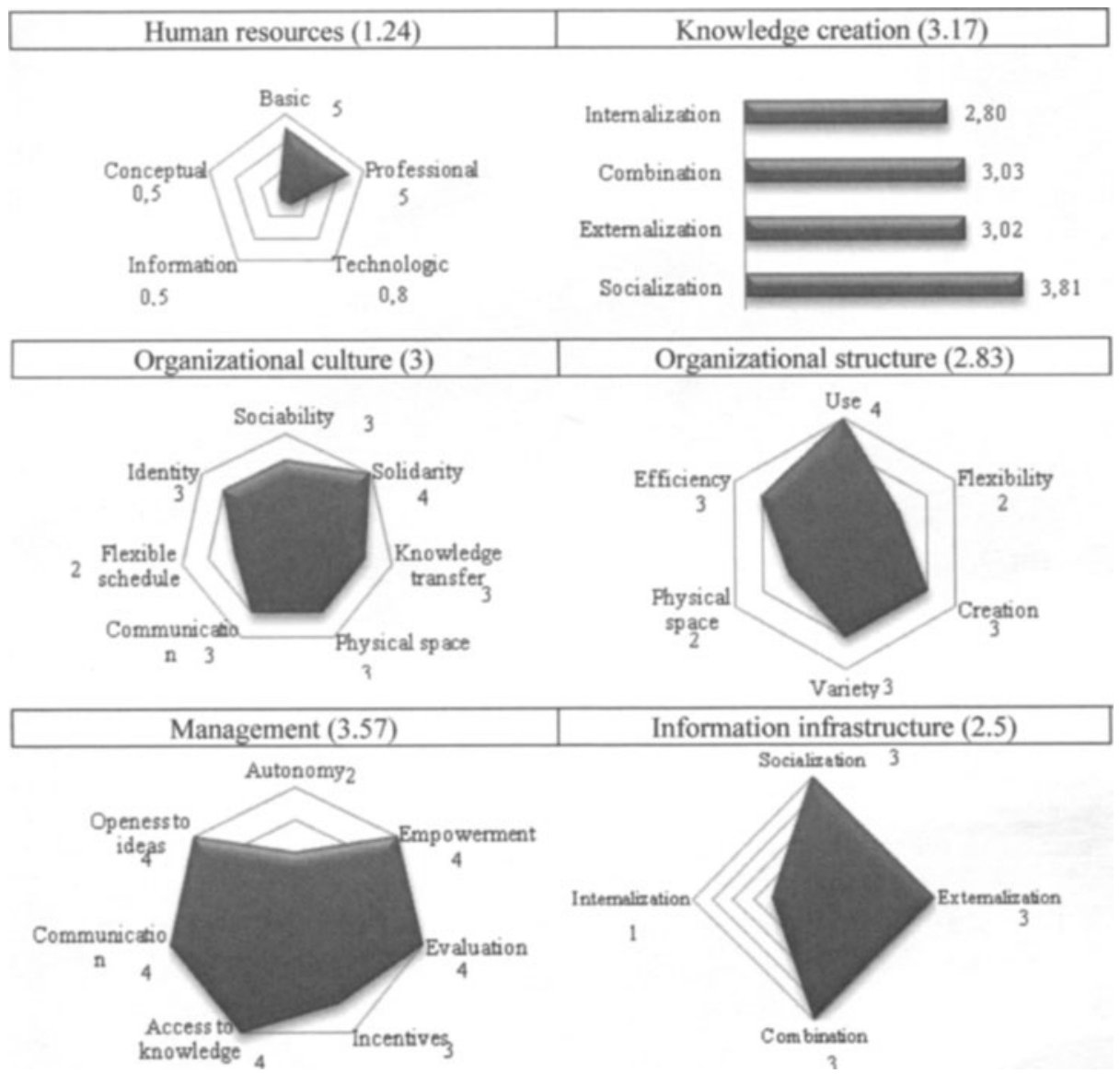

The management (3.57) at the Romanian company analyzed has the capacity and characteristics needed to support a knowledge-based organization because it supports empowerment, access to knowledge (documentation and organizational library), communication and openness to employees' ideas. The weaknesses are represented by autonomy and incentives. 
The information infrastructure (2.5) doesn't have the capacity to support a knowledge based organization because is limited to email, ERP and instant messaging (for around $20 \%$ employees).

The average of the results for the six criteria is 2.74 , which indicates that the Romanian company is a very weak knowledge based organization. The areas in which the company has to invest are: human resources (developing their technological, informational and conceptual skills), the information infrastructure (in order to support all four processes of knowledge conversion) and the organizational structure (increasing the flexibility of activating in teams and providing the physical space needed for meetings).

\subsection{Concluding remarks for the Romanian case study}

The Romanian company was analyzed at two different levels: the core and the organization itself. The core is represented by the managerial, technical and administrative staff involved in creating, developing and using the organizational strategic assets for further development of the entire organization. The second level of analysis was the organizational one which took into consideration the rest $80 \%$ of employees involved in the production division.

It was important to analyze the organization at the core level because, in the case of an investment in the organizational infrastructure (we are concentrated here on the production infrastructure) then an important number of employees might loose their jobs or we will integrate in the core level.

Table 10. Comparison between managerial, technical and administrative departments and the entire organization.

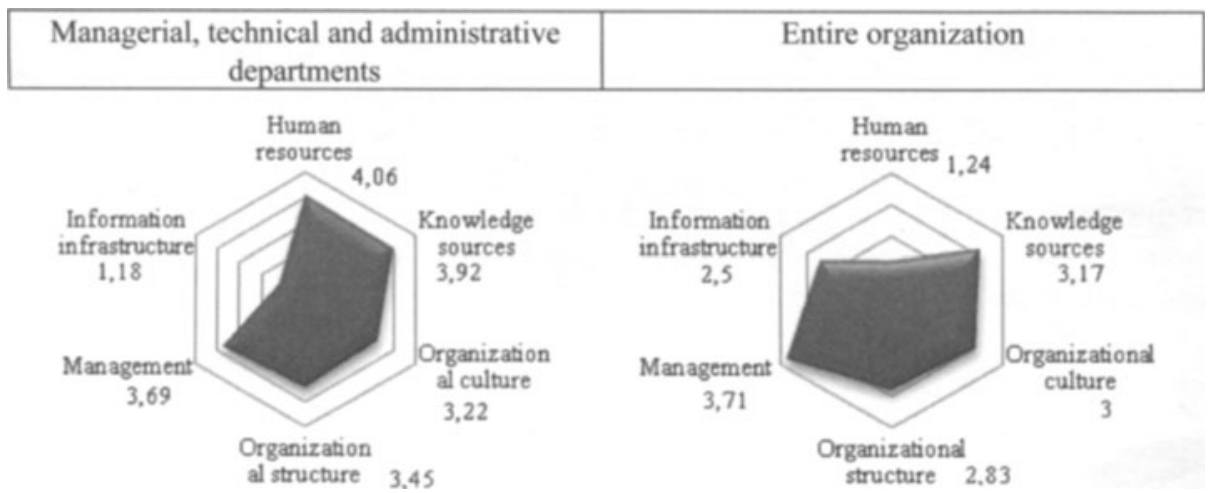

As shown in table 10, the human resources at the core level are higher qualified and specific for a knowledge-based organization than the human resources' skills at the entire organizational level.

The knowledge creation takes places mainly through combination (in the case of middle managers and administrative and technical staff) and socialization (in the case of operative employees). 
The organizational culture is characterized by high solidarity and some similarities between employees.

The organizational structure is characterized by teams, mainly in the case of operative employees, but these teams don't have a high flexibility or diversity having as members employees from the same department;

The management supports autonomy and freedom in decision making mainly in the case of managers and administrative and technical staff. The management supports learning inside organization through training and access to library's resources;

The information infrastructure is very limited and cannot cover all the four processes of knowledge creation. This information infrastructure is mainly available for top and middle managers and administrative a technical staff.

The application of this model on the Romanian case study showed the company's weaknesses and where future strategies have to be developed in order to support the organization's development. From the knowledge skills point if view, company has to support training for developing technological, problem solving and conceptual skills. The company analyzed is concerned about developing these critical skills and is in the process of creating the needed infrastructure (training center) and available training programs (with internal experts and also with companies providing professional training).

The most critical aspect is the information infrastructure, which is not capable of supporting the four knowledge creation processes. It lacks in supporting the internalization. This process takes place inside the company through training provided by internal experts, learning from mistakes and on the job training. The existent information infrastructure is supporting mainly the activity of top and middle managers, the applications are not integrated at the company level (except the ERP solution) and communication is done mainly though email, telephones and classic mail. The actual information infrastructure doesn't support learning and knowledge transfer and these are the main elements which have to be solved in the near future. A project was proposed (it is in the analysis phase) for creating an integrated management solution which will be a web-based software and will incorporate, besides the workflow management (both internally and externally - collaboration with partners), important key features like eLearning, knowledge management based and visualization and optimization tools.

\section{Conclusions}

The knowledge society implies knowledge-based organizations with the culture and management which promote knowledge transfer and support knowledge workers to constantly create knowledge trough their daily work and use, store and transfer it through the right information and communication technologies.

This paper proposes an identification model in order to highlight the strong and weak elements of the organization for the creation, use and transfer of knowledge point of view. This model is very useful in the initial phase of the analysis in case the 
company intends to implement a knowledge management strategy. The model proposed could be applied by using methods like questionnaire, interviews and direct observation and it is very useful in the SWOT analysis in case one company wants to elaborate a strategy for its future development which relies of its internal knowledge and its knowledge networks available both internally and externally.

The identification model is also useful in combination with intellectual capital models needed in the company's evaluation from the intangible assets point of view. Together, these models could highlight the weaknesses and strengths at the organizational level and could explain the intangible results.

This identification model was applied in the case of the Romanian company which is committed to its development. The results have showed that it is knowledge-based in the initial phase and has plan improvements (the IT and human resources strategy) in order to reach at least the value 4 which means good knowledge based organization capable of surviving in a dynamic and complex environment specific to knowledge economy and society.

\section{References}

1. J. Liebowitz, Knowledge organization. What every manager should know, CRC Press, 1998, p. 14

2. I. Nonaka, The Knowledge Creating Company in Harvard Business Review on Knowledge Management, 1998, pp.21-45

3. C. Argyris and D. Schon, Organizational learning - A Theory of Action Perspective, Addison-Wesley, 1978, p.29

4. P. Senge, The Fifth Discipline - The Art and Practice of the Learning Organization, Random House, 1990, p.3

5. K., M. Wiig, The Intelligent Enterprise and Knowledge Management, 2000, http://www.krii.com/downloads/intellig_enterprise $\% 20 \& \% 20 \mathrm{~km} . \mathrm{pdf}$

6. I. Nonaka, A dynamic theory of organizational knowledge creation", in Organization Science, 5 (1), 1994, pp.14-36

7. P. Drucker, The New Productivity Challenge, in Harvard Business Review, November December 1991, p.71

8. D. Collins, Knowledge Work of Working Knowledge? Ambiguity and Confusion in the Analysis of the "Knowledge Age", Employees Relations, Vol. 19(1), 1997, p.45

9. C. Despres and J. M. Hiltrop, Human Resource Management in the Knowledge Age: Current Practice and Perspectives on the Future, Employee Relations, Vol. 17(1), 1995, pp. $9-23$

10. K. Standfield, Intangible Management, Tools for Solving the Accounting and Management Crisis, Academic Press, 2002, p.9

11. M. J. Barrow and H. M. Loughlin, Towards a learning organization, Industrial and Commercial Training, 1992, vol. 24, no, 1, pp.3-7

12. Th. Davenport, Thinking for a Living - How to Get Better Performance and Results from Knowledge Workers, Harvard Business School Press, 2005, p.10

13. P. Drucker, The Coming of the New Organization, in Harvard Business Review on Knowledge Management, 1998, p.7 
14. R. Maier, Knowledge Management Systems: Information and Communication Technologies for Knowledge Management, Springer, 2002

15. P. Drucker, The Organization of the Future, Jossey Bass, 1997, pp.1-5

16. D. Johnson, KWRedux, http://www.doug-johnson.com/dougwri/KWRedux.pdf, 2005

17. I. Nonaka, I., R. Toyama, and N. Konno, SECI, Ba and Leadership: a Unified Model of Dynamic Knowledge Creation, Long Range Planning 33, pp. 5-34

18. I. Nonaka and N. Konno, The Concept of Ba: Building a Foundation for Knowledge Creation, California Management Review, Vol. 40(3) 1998, pp. 40-54

19. I. Nonaka, B. Byosiere, C. Borucki, and Konno, N., Organizational Knowledge Creation Theory: A First Comprehensive Test, International Business Review, Vol 3(4), 1994, pp. 337-351

20. R. Goffee and G. Jones, Organizational Culture: A Sociological Perspective in Cooper, C.L., Cartwright, S., Earley, P.S., in The Organizational Handbook of Organization Culture and Climate, Willey, 2001, pp.3-20 